\title{
Development of a training program to support health care professionals to deliver the SPACE for COPD self-management program
}

This article was published in the following Dove Press journal:

International Journal of COPD

7 June 2017

Number of times this article has been viewed

\section{Claire Blackmore' \\ Vicki L Johnson- \\ Warrington ${ }^{2}$ \\ Johanna EA Williams ${ }^{2}$ \\ Lindsay D Apps ${ }^{2}$ \\ Hannah ML Young ${ }^{2}$ \\ Claire LA Bourne ${ }^{2}$ \\ Sally J Singh ${ }^{2}$}

'Kettering General Hospital National Health Service (NHS) Trust, Kettering, Northamptonshire, ${ }^{2}$ Centre for

Exercise and Rehabilitation Science, Leicester Respiratory Biomedical Research Unit, University Hospitals of Leicester NHS Trust, Leicester, UK
Correspondence: Sally J Singh

Centre for Exercise and Rehabilitation

Science, Leicester Respiratory Biomedical

Research Unit, University Hospitals

of Leicester NHS Trust, Groby Road,

Leicester, LE3 9QP, UK

Email sally.singh@uhl-tr.nhs.uk
Background: With the growing burden of COPD and associated morbidity and mortality, a need for self-management has been identified. The Self-management Programme of Activity, Coping and Education for Chronic Obstructive Pulmonary Disease (SPACE for COPD) manual was developed to support self-management in COPD patients. Currently, there is no literature available regarding health care professionals' training needs when supporting patients with COPD on self-management.

Aim: This study sought to identify these needs to inform, design and develop a training program for health care professionals being trained to deliver a self-management program in COPD.

Methods: Fourteen health care professionals from both primary and secondary care COPD services participated in face-to-face semistructured interviews. Thematic analysis was used to produce a framework and identify training needs and views on delivery of the SPACE for COPD self-management program. Components of training were web-based knowledge training, with preand posttraining knowledge questionnaires, and a 1-day program to introduce the self-management manual. Feedback was given after training to guide the development of the training program.

Results: Health care professionals were able to identify areas where they required increased knowledge to support patients. This was overwhelming in aspects of COPD seen to be outside of their current clinical role. Skills in goal setting and behavioral change were not elicited as a training need, suggesting a lack of understanding of components of supporting self-management. An increase in knowledge of COPD was demonstrated following the training program.

Conclusion: Both knowledge and skill gaps existed in those who would deliver self-management. Analysis of this has enabled a training program to be designed to address these gaps and enable health care professionals to support patients in self-management.

Keywords: self-management, COPD, health care professionals, training, development

\section{Introduction}

COPD is a disorder characterized by airflow obstruction, which is thought to affect up to three million people in the UK. ${ }^{1}$ Worldwide, it is the fourth leading cause of death and is one of the leading causes of hospitalization and associated health costs. ${ }^{2}$ Management of the condition is complex but can include smoking cessation, optimization of pharmacological therapies, pulmonary rehabilitation and strategies focusing on the identification and treatment of exacerbations. ${ }^{3}$ Self-management, defined as "the systematic provision of supportive interventions designed to increase patients' skills in decision-making, problem-solving, utilizing resources and taking action," is increasingly becoming part of the management of chronic disease. 


\begin{tabular}{|c|c|c|c|c|c|c|c|c|c|c|c|c|c|c|}
\hline $\begin{array}{c}\text { Identify } \\
\text { training needs }\end{array}$ & $\Rightarrow$ & $\begin{array}{c}\text { Evaluate } \\
\text { training needs }\end{array}$ & $\Rightarrow$ & $\begin{array}{c}\text { Pretraining } \\
\text { knowledge } \\
\text { questionnaire }\end{array}$ & $\Rightarrow$ & $\begin{array}{l}\text { Web-based } \\
\text { training }\end{array}$ & $\Rightarrow$ & $\begin{array}{l}\text { Provision } \\
\text { of manual }\end{array}$ & $\Rightarrow$ & $\begin{array}{c}\text { Training } \\
\text { day }\end{array}$ & $\Rightarrow$ & $\begin{array}{l}\text { Posttraining } \\
\text { knowledge } \\
\text { questionnaire }\end{array}$ & $\Rightarrow$ & $\begin{array}{l}\text { Evaluation } \\
\text { of training }\end{array}$ \\
\hline
\end{tabular}

Figure I Flowchart of program development.

Within the UK, increasing financial constraints within health care has led to a recent focus on efficiency savings. ${ }^{5}$ One element of this is a proposal to promote empowerment of patients to manage chronic health conditions through evidence-based approaches, including self-management educational courses. With $\sim 15$ million patients in the UK living with long-term conditions accounting for $\sim 50 \%$ of GP appointments and $70 \%$ of inpatient bed days, ${ }^{6}$ it is clearly of importance to increase patients' confidence in managing their conditions through self-management. This has the potential both for financial savings and to improve patients' quality of care and outcomes.

Patient education and self-management programs have been delivered in other important long-term conditions (including chronic kidney disease $\mathrm{s}^{7,8}$ and type 2 diabetes $^{9}$ ), and there is now an increasing body of evidence supporting selfmanagement in $\mathrm{COPD}^{10-13}$ and its economic viability. ${ }^{12,14}$

The Self-Management Programme of Activity, Coping and Education (SPACE) for COPD is a structured selfmanagement intervention incorporating exercise, education and psychosocial support. ${ }^{15}$ Its aims are to support people with COPD in managing day-to-day tasks, minimizing the burden of symptoms, enhance emotional well-being and initiate behavior change. ${ }^{16}$ It is a self-directed program introduced by health care professionals trained in motivational interviewing, which the patients can complete in their own time, utilizing the SPACE for COPD manual. The manual is designed to develop both generic self-management skills (including problem-solving, decision-making, effective utilization of resources and taking action) and tasks focused on disease-specific issues such as chest clearance, breathing control and several educational sections. ${ }^{16}$ Patients work through the manual at home over $\sim 6$ weeks and receive telephone support from health care professionals. It was developed by both health care professionals and patients at University Hospitals of Leicester NHS Trust in 2007 and has been piloted successfully in primary care, demonstrating a significant decrease in dyspnea and increase in exercise capacity. ${ }^{15}$ It has also been shown that when delivered and supported by a health care professional, the manual elicits significant gains in disease knowledge, exercise performance and reduction in anxiety compared to usual care, in primary care, ${ }^{16}$ and was shown in secondary care to improve dyspnea and endurance capacity to a level similar to that of pulmonary rehabilitation. ${ }^{17}$ However, the health care professionals delivering the SPACE for COPD manual need extensive knowledge in COPD to advise patients further about their condition and skills in motivational interviewing and goal setting to support behavior change. ${ }^{15}$

Many studies have documented the perceptions of health care professionals regarding what patients need to do differently to self-manage their condition, but there has been little written on the role of the delivery of programs and their outcomes. ${ }^{18}$ It has been shown in previous studies that patients want self-management programs to be delivered by health care professionals who are knowledgeable about COPD and physical activity, as well as familiar with the patients and their capabilities. ${ }^{15}$ There is increasing recognition of the importance of training health care professionals in delivering self-management training to maximize the effectiveness ${ }^{6}$ but barriers remain in both the approach of the health care professionals' (and their understanding of) self-management and the organization of health practices themselves. ${ }^{19}$

The purpose of this study was to understand the training needs of health care professionals to deliver a self-management program to patients with COPD and to develop a package of training in response to these needs. The sequence of this development of training is shown in Figure 1.

\section{Methods \\ Ethical approval}

The semistructured interviews were approved by the Local Research Ethics Committee (LREC), University Hospitals of Leicester R\&D, Leicestershire, Northamptonshire and Rutland Primary Care Research Alliance (LNR-PCRA) and the West Midlands South Comprehensive Local Research Network (07/H0408/114). Written informed consent was provided by all health care professionals who agreed to participate. There was no patient contact during this research.

\section{Evaluation of training needs Design}

A semistructured one-to-one interview methodology was chosen to enable key themes to be elicited from discussions 
with participants. This ensured that core questions surrounding training were asked, but with flexibility for probing the participants' answers to provide a more informative response. The interviews were conducted by a research physiotherapist, who was unknown to all participants, in a private setting within the participant's workplace.

\section{Study population}

The sample comprised 14 health care professionals, all of whom were female, who had been working within both primary and secondary care COPD services within the previous year. It was felt this group of professionals would be reasonably expected to deliver the manual and so were well placed to develop and test the prototype training program. Health care professionals who responded to adverts for participants were invited to a semistructured interview, all of which took place during 2010 and 2011.

\section{Procedure}

Health care professionals were recruited via National Health Service (NHS)-related websites within specific primary care trusts, hospital-based intranet websites, poster advertisements and mail outs to practice managers. Those responding were given a participant information sheet and completed a reply slip in order for the research team to contact them. An interview schedule (Supplementary materials) which included open-ended questions and probes to facilitate further discussion was developed. This was informed by both a literature review and the research team's previous experience of supporting self-management. Participants provided written informed consent to their semistructured interview being audio recorded. These were professionally transcribed verbatim. Interviews lasted between 35 and 90 minutes, and each participant was given a SPACE for COPD manual to peruse prior to the interview for discussion.

\section{Data analysis}

Thematic analysis of the interviews was undertaken by multidisciplinary health care professionals working in research: HMLY and LDA. All had experience in qualitative research, as well as knowledge of COPD and self-management. The process of analysis followed steps as described by Braun and Clarke. ${ }^{20}$ This involved independent familiarization with the data, coding and identification of initial themes. All parties then came together to refine themes, reviewing and defining them further, resulting in a thematic map being produced with names for the different levels of themes being agreed by all authors. The process was fluid and transparent, with movement in both directions between stages as new themes emerged and new relationships were recognized. Ongoing discussions were held with the wider multidisciplinary team to resolve disagreements and gain a fuller understanding of the participant's discourse. This ensured consistency in results through investigator triangulation.

\section{Development of the training program}

Based on data from the semistructured interviews, a framework was created to address training needs. A steering group was established to develop the training program, comprising health care professionals with and without previous expertise, a nurse educationalist for the acute trust and representatives from a website technology company (www.hark2.com). After discussion between researchers around the required knowledge and skills to deliver the SPACE for COPD manual, it was logically derived that the training program should consist of two components: a web-based training program (in collaboration with an external provider) and a face-to-face training day delivered by health care professionals involved in delivering the SPACE for COPD manual.

\section{Web-based training program}

The web-based training program was designed to take $\sim 6$ hours to complete and had four distinct sections: a knowledge assessment (Bristol COPD Knowledge Questionnaire, BCKQ); ${ }^{21}$ an educational section, providing information on COPD, health promotion approaches and health behavior change skills; an introduction to self-management and the support of self-management using SPACE for COPD, and retest of knowledge upon completion of the course. A score of $70 \%$ on the knowledge questionnaire was mandatory to progress to the face-to-face training. At the end of some sections, there were additional short videos focusing on motivational interviewing, demonstrating the specific techniques used. To allow ongoing support, there was also the facility for participants to utilize an "ask the expert" tool, whereby they could have direct contact with a health care professional experienced in the delivery of the SPACE for COPD manual if necessary.

\section{Training day}

The face-to-face training day was developed to assess health care professionals' competency at introducing and supporting self-management. It took place over 1 day with a combination of taught skills and demonstrations of manual delivery. Experienced health care professionals who were already delivering the SPACE for COPD program delivered the 
face-to-face training, including manual demonstrations and question-and-answer sessions. It was important for trainers to have prior experience of delivering the manual to improve credibility of the training. At the end of the day, there was time set aside for trainees to speak to the trainers to ask any further questions they had. Following this training day, health care professionals were asked to provide feedback in order to make any necessary amendments and alterations to the program. Once the web-based training program and training day were completed, participants received a certificate of competency to deliver and support self-management of COPD.

\section{Feedback of the training program}

After initial development of the website with continual informal feedback, alpha (a form of internal user acceptance) and beta (a form of external user acceptance) testing of the site was carried out with potential users. These users had responded to the advert and were representative of those who may be expected to attend training and deliver the SPACE for COPD manual, but who did not go on to receive face-to-face training. Patterns within the BCKQ knowledge data were then analyzed to assess the different COPD knowledge domains ${ }^{21}$ to ensure that the training program covered the areas with the lowest scores and gave information on the wide range of topics within the knowledge questionnaire.

\section{Results}

\section{Evaluation of training needs}

A total of 35 nurses and allied health professionals received information regarding the study, with 18 expressing an interest in participating in interviews. Of these, 14 agreed to participate after two were unable to attend and two were not eligible for the study due to working outside the region covered by ethical approval. None of those who took part in the interview process had undertaken specific self-management training with respect to COPD. Although the professional backgrounds showed limited variation, they included most professionals who would be expected to deliver the SPACE for COPD program. Their characteristics are summarized in Table 1.

\section{Thematic analysis}

Five themes initially emerged during the thematic analysis process. This was later changed after refinement of two weaker themes, which easily merged. This created four key themes: "Educational needs and training topics", "Preferred methods of training delivery", "Posttraining support needs" and "Potential challenges to process". Within these key
Table I Participant demographics $(n=\mid 4)$

\begin{tabular}{ll}
\hline & Number (\% of total) \\
\hline Gender & $14(100)$ \\
Female & \\
Ethnicity & $12(85.7)$ \\
White British & $\mathrm{I}(7.1)$ \\
African Caribbean & $\mathrm{I}(7.1)$ \\
Missing information & \\
Profession & $3(21.4)$ \\
Physiotherapist & $3(21.4)$ \\
Respiratory research nurse & $3(21.4)$ \\
Practice nurse & $2(14.3)$ \\
Community respiratory nurse & $\mathrm{I}(7.1)$ \\
Respiratory nurse & $\mathrm{I}(7.1)$ \\
Nurse practitioner & $\mathrm{I}(7.1)$ \\
Occupational therapist & \\
Grade & $8(57.1)$ \\
Specialized & $5(35.7)$ \\
Highly specialized & $\mathrm{I}(7.1)$ \\
Missing information & $18.88(10.3 \mathrm{I})$ \\
Mean years NHS experience (SD) & $7.53(5.3 \mathrm{I})$ \\
Mean years respiratory care experience (SD)
\end{tabular}

Abbreviations: NHS, National Health Service; SD, standard deviation.

themes are between two and five master themes and several subthemes.

\section{Key theme I: educational needs and training topics}

All participants recognized the importance of knowledge of the professionals who would be introducing the SPACE for COPD manual. Most were comfortable with the knowledge associated with their area of speciality, but acknowledged areas where they would benefit from COPD-specific teaching, including oxygen for traveling and physical activity, specifically sexual activity. Understandably, delivery of the manual itself was also identified as a training need. Many felt that they would need some assistance with following the stages of the manual, some querying the flexibility of the stages and devising action plans with the patients. Discussion around the outcome measures tended to focus on health care professionals being unfamiliar with the measures used to quantify exercise tolerance and a preference for focusing on quality of life in addition to exercise capacity. Communication skills were identified that would aid facilitation of the manual, with the most common skill the participants felt that they needed to develop being identified as dealing with distress. Many health care professionals spoke of a reluctance to discuss low mood as they felt unable to manage the response or the emotions of the patient potentially arising from this (refer to Table 2 for example quotations). 
Table 2 Key theme I - educational needs and training topics, exemplar quotations

\begin{tabular}{|c|c|c|}
\hline Master theme & Subtheme & Example \\
\hline \multirow[t]{8}{*}{ COPD-specific knowledge } & Anatomy and physiology & $\begin{array}{l}\text { "If you were running this for people who'd never been involved in patients with COPD } \\
\text { you'd have to have longer than a day to teach them about the disease" [Occupational } \\
\text { therapist, secondary care] }\end{array}$ \\
\hline & $\begin{array}{l}\text { Exacerbations and disease } \\
\text { progression }\end{array}$ & $\begin{array}{l}\text { "Thinking about advanced disease }[\ldots] \text { that's quite a shock and I don't think we're } \\
\text { confident to discuss that with them" [Physiotherapist, secondary care] }\end{array}$ \\
\hline & Exercise & $\begin{array}{l}\text { "I'm not an expert in exercising or anything like that so all of it really is stuff that I could } \\
\text { probably do with a bit more in depth information on" [Respiratory nurse, secondary care] }\end{array}$ \\
\hline & Sex and relationships & $\begin{array}{l}\text { "I think the area on relationships and talking about sex is [something] that a lot of people } \\
\text { don't cover and feel uncomfortable covering" [Nurse practitioner, primary care] }\end{array}$ \\
\hline & Diet and eating & $\begin{array}{l}\text { "I wouldn't be brilliant at food, trying to get patients to eat a nice healthy diet" } \\
\text { [Respiratory nurse, secondary care] }\end{array}$ \\
\hline & $\begin{array}{l}\text { Breathing and inhaler } \\
\text { techniques }\end{array}$ & $\begin{array}{l}\text { "It's always good just to go over [inhaler techniques] with you to make sure you are } \\
\text { right because things change and these are the sort of things you need to pass on to your } \\
\text { patients" [Respiratory nurse, secondary care] }\end{array}$ \\
\hline & Oxygen and traveling & $\begin{array}{l}\text { "People ask about taking oxygen on holiday and that's normally something I have to go off } \\
\text { and find out rather than just having the knowledge there" [Physiotherapist, secondary care] }\end{array}$ \\
\hline & Awareness of resources & $\begin{array}{l}\text { "I never really know what's out there for them [carers for people with COPD]" } \\
\text { [Community respiratory nurse] }\end{array}$ \\
\hline \multirow[t]{2}{*}{ Delivery of manual } & How to follow stages & $\begin{array}{l}\text { "What I would want to know is do they have to follow stage one, two, three and four } \\
\text { or can they do stage one, look at stage three - can it be flexible?" [Respiratory nurse, } \\
\text { secondary care] }\end{array}$ \\
\hline & Action plan & $\begin{array}{l}\text { "The bit that I would want to see quite a lot more on is definitely the action plan, and } \\
\text { about doing an action plan with the patient" [Nurse, secondary care] }\end{array}$ \\
\hline \multirow[t]{2}{*}{ Outcome measures } & Administration & $\begin{array}{l}\text { "[With] the outcome measures, if you've not been involved in rehabilitation the chances } \\
\text { are you won't be familiar with how you do [them]" [Physiotherapist, secondary care] }\end{array}$ \\
\hline & Interpretation & $\begin{array}{l}\text { "What would I be looking for to show that there had been a change? It's just not } \\
\text { something that we'd do" [Respiratory nurse, secondary care] }\end{array}$ \\
\hline \multirow[t]{4}{*}{ Communication skills } & Confidence to listen & $\begin{array}{l}\text { "You need to be able to listen to the patient about what they want" [Occupational } \\
\text { therapist, secondary care] }\end{array}$ \\
\hline & Imparting information & $\begin{array}{l}\text { "A lot of the ideas that are second nature to you are absolutely brand new to patients" } \\
\text { [Respiratory nurse, secondary care] }\end{array}$ \\
\hline & Appropriate language & $\begin{array}{l}\text { "A lot of the terminology that is second nature to you is absolutely brand new to patients" } \\
\text { [Nurse practitioner, primary care] }\end{array}$ \\
\hline & $\begin{array}{l}\text { Dealing with difficult } \\
\text { emotions }\end{array}$ & $\begin{array}{l}\text { "I get a lot of anger from people who did give up smoking but }[\ldots] \text { five years down the line } \\
\text { after quitting smoking they've still got a diagnosis of COPD and they didn't realise that that } \\
\text { was a potential issue" [Respiratory nurse, secondary care] }\end{array}$ \\
\hline
\end{tabular}

\section{Key theme 2: preferred methods of training delivery}

There was a marked preference for group-based face-to-face training. Participants felt this method allowed the group members the opportunity to ask questions, share experience and facilitate discussion, as well as receive "hands-on" training. The participants also favored observing other professionals who were experienced in delivering the SPACE for COPD manual, either via face-to-face visits or by watching recordings of them introducing the manual. E-Learning was a popular form of training, although some participants were concerned this method might be disjointed and that it may be possible to complete the training without demonstrating a full understanding of the material (refer to Table 3 for example quotations).

\section{Key theme 3: posttraining support needs} While all health care professionals felt that follow-up support was a crucial component of the delivery of SPACE for COPD program, there was no consensus on the form, environment and frequency that would be necessary. Suggestions included telephone follow-up, face-to-face reviews and a reassessment of competence. Some participants felt that observed follow-up should be decided in partnership with the patient, but that the design of services in which they worked may not support this (refer to Table 4 for example quotations).

\section{Key theme 4: potential challenges to the process}

Health care professionals were concerned that the SPACE for COPD manual might not suit all patients, voicing 
Table 3 Key theme 2 - preferred methods of training delivery, exemplar quotations

\begin{tabular}{|c|c|c|}
\hline Master theme & Subtheme & Example \\
\hline \multirow[t]{6}{*}{ Face-to-face training } & $\begin{array}{l}\text { Opportunity to ask } \\
\text { questions }\end{array}$ & $\begin{array}{l}\text { "A study day run by health care professionals who work in this area would be beneficial and } \\
\text { then people can ask questions" [Occupational therapist, secondary care] }\end{array}$ \\
\hline & Practice manual delivery & $\begin{array}{l}\text { "l'd like to work through it with someone that had been involved in setting it up and knew } \\
\text { what they actually are looking for" [Respiratory nurse, secondary care] }\end{array}$ \\
\hline & $\begin{array}{l}\text { Manual delivery } \\
\text { demonstrations }\end{array}$ & $\begin{array}{l}\text { "A DVD would be a simple way you could do a team teaching session, stick the DVD in and } \\
\text { watch it" [Physiotherapist, secondary care] }\end{array}$ \\
\hline & $\begin{array}{l}\text { Demonstrate exercise } \\
\text { section }\end{array}$ & $\begin{array}{l}\text { "Particularly [for] the exercise part you need a hands on, demonstrated part rather than just } \\
\text { sitting and talking about it" [Respiratory nurse, secondary care] }\end{array}$ \\
\hline & $\begin{array}{l}\text { Observe motivational } \\
\text { process }\end{array}$ & $\begin{array}{l}\text { "l'd love to see [the manual] in action and how [the health care professional] talks to the } \\
\text { patients and motivates them" [Respiratory nurse, secondary care] }\end{array}$ \\
\hline & Group interaction & $\begin{array}{l}\text { "When you actually get together }[. . .] \text { you'll bounce off each other's ideas }[\ldots] \text { sometimes the } \\
\text { most simplest ideas come out of group discussions" [Occupational therapist, secondary care] }\end{array}$ \\
\hline \multirow[t]{2}{*}{ Self-study } & Manual familiarization & $\begin{array}{l}\text { "I would really need to spend a lot of time looking through it myself and getting to know it" } \\
\text { [Community respiratory nurse, primary care] }\end{array}$ \\
\hline & Independent study & $\begin{array}{l}\text { "Blood gases and patients retaining things and being hypoxic [...] I think on those more } \\
\text { medical things I need to brush up on" [Occupational therapist, secondary care] }\end{array}$ \\
\hline Observations & Allied COPD services & $\begin{array}{l}\text { "I keep meaning to go and visit the pulmonary rehab, I've been years ago and I've seen what } \\
\text { I can remember of what goes on there, but it wouldn't hurt to go again and just update [...] } \\
\text { and any ideas that I can pick up on that they can give me" [Community respiratory nurse] }\end{array}$ \\
\hline \multirow[t]{3}{*}{ E-Learning } & Accessibility & $\begin{array}{l}\text { "Face-to-face training might be difficult, I think e-learning might be an idea as you can access } \\
\text { it from anywhere as long as you have a computer" [Physiotherapist, secondary care] }\end{array}$ \\
\hline & $\begin{array}{l}\text { Demonstrate } \\
\text { understanding }\end{array}$ & $\begin{array}{l}\text { "You could be assessed as to whether you've got the right amount of knowledge" [Research } \\
\text { physiotherapist] }\end{array}$ \\
\hline & Engagement with material & $\begin{array}{l}\text { "I find it very easy to switch off when I am trying to do e-learning" [Respiratory research } \\
\text { nurse, secondary care] }\end{array}$ \\
\hline
\end{tabular}

concerns over language and literacy barriers and cognitive dysfunction, as well as the size of the manual intimidating some patients. However, this concern was not well founded, with no patients mentioning this during a pilot study of the manual, ${ }^{15}$ which was developed with patients. In addition to motivation of the patients, other identified barriers included ability to attend follow-up, desire for a paternalistic model of care, guilt due to feeling their illness is self-inflicted, language barrier, cognitive deficits and literacy. Health care professionals described feeling unsure how to identify those patients who might gain most from the program and were more highly motivated, and for some this was important to ensure that their time was invested in appropriate patients. This was linked to the other concern voiced, which was the already large workload of many of the health care professionals. Challenges were also created by many not working solely with COPD patients and some rarely encountered patients with COPD in their clinical practice. This increased and varied workload, together with a lack of time, meant that resources were

Table 4 Key theme 3 - posttraining support needs

\begin{tabular}{|c|c|c|}
\hline Master theme & Subtheme & Example \\
\hline \multirow[t]{3}{*}{$\begin{array}{l}\text { Undertaking assessment } \\
\text { of competence }\end{array}$} & Observations & $\begin{array}{l}\text { "It'd be quite useful to know that you were going about working with [the manual] in the } \\
\text { right way but I can't think of how you would assess that other than having someone watch }\end{array}$ \\
\hline & & you with a patient and then give you feedback on it" [Physiotherapist, secondary care] \\
\hline & Face-to-face reviews & $\begin{array}{l}\text { "[We need] a month's review to see how we're getting on with using [the manual] and } \\
\text { then whether we need any further training from that" [Physiotherapist, secondary care] }\end{array}$ \\
\hline \multirow[t]{3}{*}{ Follow-up support } & Group sessions & $\begin{array}{l}\text { "They're usually done in small groups, the diabetes ones are, and it would be good to do } \\
\text { the same for COPD, just small groups" [Practice nurse] }\end{array}$ \\
\hline & Updates & $\begin{array}{l}\text { "If there's any changes, any updates, anything new that's happening, that would be } \\
\text { quite good online }[\ldots] \text { just to keep informed of what's going on really in the service" } \\
\text { [Community respiratory nurse] }\end{array}$ \\
\hline & Expert advice & $\begin{array}{l}\text { "I think you'd need [...] a person that you can contact if you're struggling with any } \\
\text { component of the manual once you're out there running it yourself" [Research } \\
\text { physiotherapist] }\end{array}$ \\
\hline
\end{tabular}


Table 5 Key theme 4 - challenges to the process

\begin{tabular}{|c|c|c|}
\hline Master theme & Sub-theme & Example \\
\hline \multirow[t]{3}{*}{$\begin{array}{l}\text { Challenges to health care } \\
\text { professional training }\end{array}$} & Cost & $\begin{array}{l}\text { "If the training course was very expensive then trying to justify it would be more } \\
\text { difficult" [Physiotherapist, secondary care] }\end{array}$ \\
\hline & Time & $\begin{array}{l}\text { "I think that the pressures we have now to [prove] what we are doing clinically, to } \\
\text { actually be taking more time out of work would be frowned upon" [Respiratory } \\
\text { nurse, secondary care] }\end{array}$ \\
\hline & Location & $\begin{array}{l}\text { "I suppose it's location isn't it, I suppose if you were delivering a thing in Coventry } \\
\text { it's when's a good time, are you going to do it in the day and people get time off } \\
\text { work to come" [Physiotherapist, secondary care] }\end{array}$ \\
\hline Challenges to delivery of & Time & "You are on a time limit as well, you've got to watch your timing" [Practice nurse] \\
\hline \multirow[t]{5}{*}{ SPACE for COPD manual } & Contact with patients & $\begin{array}{l}\text { "Actually l'd like to see you [the patient] four more times to talk through how } \\
\text { you can manage yourself better and realising that actually the patient may not have } \\
\text { the time or the inclination to come in and have all those extra appointments" } \\
\text { [Community respiratory nurse] }\end{array}$ \\
\hline & Cost of manual & $\begin{array}{l}\text { "You might be presented with this beautiful book, which I don't know how much } \\
\text { it costs, but I wouldn't imagine it's that cheap to put out, so we could be wasting } \\
\text { money for it just to prop up the coffee table or whatever" [Physiotherapist, } \\
\text { secondary care] }\end{array}$ \\
\hline & Size of manual & $\begin{array}{l}\text { "It would look a bit overwhelming although just because of its size I think" } \\
\text { [Community respiratory nurse] }\end{array}$ \\
\hline & Follow-up assessments & $\begin{array}{l}\text { "If we work through a particular section }[\ldots] \text { and make a note of that }[\ldots] \text { and } \\
\text { then come back and see if they've got any improvements" [Practice nurse] }\end{array}$ \\
\hline & Identify suitable patients & $\begin{array}{l}\text { "This age group there might be elements of dementia creeping in" [Community } \\
\text { respiratory nurse] }\end{array}$ \\
\hline
\end{tabular}

Abbreviation: SPACE, Self-Management Programme of Activity, Coping and Education.

often limited and could impact on training (refer Table 5 for quotation examples).

\section{Program development}

The structure of the training program is detailed subsequently. This was devised through discussion between the researchers and was informed by the semistructured interviews, the need for an objective test of knowledge, and participant feedback. Due to concerns over time pressures within the health care professionals, it was condensed into the following sections:

1. Web-based training with knowledge questionnaire covering the basics of COPD and motivational interviewing techniques to allow participants to familiarize themselves prior to face-to-face training (provision of SPACE for COPD manual prior to face-to-face training).

2. Face-to-face workshop utilizing presentations and practical skill sessions to cover principles of self-management, motivational interviewing, introducing the SPACE for COPD manual and additional time for group discussion, reflection and questions.

3. Follow-up posttraining.

It is estimated that it will take 6 months for training completion as a longer duration would risk a lapse of skills and knowledge. It is also recommended that a 12-month review of skills be undertaken to ensure the standardized quality of manual delivery.

\section{Training program feedback}

A total of 55 health care professionals evaluated the webbased training program. These professionals did not participate in the semistructured interviews or training day. Nine evaluated the web-based training using alpha testing, 11 using beta testing and 35 completed the pre- and postcourse knowledge questionnaire. The web-based training program was generally well received, with the main feedback being focused on some technical issues, as some problems were found with browser compatibility. Other feedback informed the development team that there was no evidence of completion of each module of the training, making it difficult to track which modules had been completed. As a result of this feedback, each module received a tick once it had been completed, and a notification was placed on the website to remind health care professionals each time they accessed the program.

The BCKQ was administered both before and after the training program. The 35 health care professionals who completed the prototype web-based training program increased their knowledge from a pretraining average of $81 \%(\mathrm{SD}=6.0)$ to a posttraining average of $92 \%(\mathrm{SD}=3.8)$. 
Feedback from the participants on the 1-day training program was largely positive, with comments on the written evaluation forms including "useful study day to clarify some issues", "practical demonstration very helpful" and "fantastic study day, very informative". It was noted that the motivational interviewing section was particularly helpful, with one attendee stating that she found the session "new and informative". The handouts were also found to be useful, with trainees able to re-refer to these as necessary before implementing the manual. Participants requested more information regarding exercise prescription in the presentations, which was subsequently incorporated into the program for future training. This consisted of an expected duration of walking for given Medical Research Council dyspnea scores, practical tips to share with patients (such as walking on a flat gradient, walking at a brisk pace and to aim to increase by a few seconds each day) and things patients should be aware of (such as ensuring walking aids are used if needed, the likelihood of walking quicker without realizing, and having bad days).

Feedback was also given regarding the implementation of the manual and the training program as a whole. Health care professionals who responded to this question had concerns regarding the resources, referral pathway and time needed to complete the training and attend the training day. There was uncertainty about where the funding for this would come from and how the referral pathway could be simplified to ensure that the SPACE for COPD manual could be targeted to those patients who would benefit most from it.

\section{Discussion}

This description of the development of a training program tailored to the SPACE for COPD manual delivery is likely to be the first attempt to standardize both learning and training in this area. Consulting with health care professionals enabled the subsequent training program to be tailored to the identified needs of the participants, and feedback allowed the program to be modified to optimize delivery.

\section{Health care professional knowledge}

The need for knowledge-based training has been highlighted in the use of the BCKQ. Although designed for use by patients with COPD to assess knowledge of their condition, this questionnaire was used in the absence of any alternative knowledge questionnaires for health care professionals. The results from the BCKQ dictated the content of the knowledgebased training, drawing particular attention to breathlessness and use of inhaled steroids in COPD. This knowledge deficit in breathlessness is interesting as this is a characteristic symptom of COPD and is used to both assist diagnosis and guide further management of the disease.

The knowledge gaps identified by the BCKQ were addressed with the assistance of interactive web-based presentations that were uploaded to the web-based training program to help improve these deficits. It is hoped that this increase in knowledge will also increase confidence in dealing with patient enquiries.

\section{Semistructured interviews}

The collection of qualitative data through semistructured interviews guided the development of the structure and content for face-to-face training days and subsequent follow-up. The majority of training needs identified were regarding knowledge deficits and manual-specific needs, such as being familiar with the manual prior to delivery, rather than specific communication skills required to optimize delivery of the manual. This is despite key skills such as goal setting and behavioral change skills, in particular motivational interviewing skills, forming a crucial part of the manual delivery. Behavior change is seen as a central concept in self-management. ${ }^{22}$ Given that this was not flagged up during interviews as an area for training to address, this may suggest a lack of understanding of the key components of self-management and behavior change on behalf of the health care professionals. A previous study into self-management in primary care has found that motivational techniques, instead of educating those who do not wish to engage, are recognized as being important but very difficult to put into practice, with a training program in primary care having to schedule extra sessions on motivational techniques. ${ }^{21}$ It will also help guide the support needed in follow-up, with some health care professionals likely to need a higher degree of support in the months following training.

Another interesting finding was the tendency for many of those with a higher level of experience to suggest more training would be needed for those with less experience, though these participants felt the training would be sufficient as long as adequate follow-up was provided. However, those experienced in goal setting and motivational interviewing still felt that the training day could be a useful refresher for these skills.

\section{Training program feedback}

As a result of the feedback from the health care professionals attending the training day, subsequent training has increased the number of demonstrations of manual delivery 
by facilitators, as well as the information given on exercise prescriptions. An additional alteration was the introduction of a crib sheet, which attendees could later use to act as an aide-memoire when they were first introducing the SPACE for COPD manual.

\section{Program evaluation}

It was felt that the largest barrier to implementing the manual was time, with health care professionals, from all specialties asked, believing that it could be difficult to set aside the time from clinical commitments to complete the training. This was acknowledged when developing the training program, with the web-based section being designed so that it could be completed in small, manageable sessions, progress being saved when the health care professional logged off from the service. The training program can also be updated to reflect any new guidelines or changes in current best practice, which enables health care professionals to keep their knowledge and skills up to date.

With respect to quality assurance, performance indicators for the program included appropriate knowledge to support COPD patients, establishing a collaborative relationship with the patient, and patients demonstrating outcomes which show the self-management principles have been employed. This was observed using the BCKQ, a log of manual introductions delivered to patients and practice visits by facilitators. Targets were set for six patients to be introduced to the manual in the first 3 months after training and at least 12 manual introductions per year.

\section{Limitations}

A limitation of the study is the use of the BCKQ. It has been used in this context to assess the knowledge base of the health care professionals undergoing training and to track any improvements in knowledge following the training, but the questionnaire was designed for use in patients, not health care professionals, and has not been validated for this population. ${ }^{23}$ However, in the absence of a questionnaire which is valid for health care professionals, it was considered to be the most feasible way of measuring knowledge. It is not clear whether these improvements in knowledge were sustained, or if knowledge was linked to level of experience.

In some circumstances, lay persons are being trained to support self-management programs. Due to the SPACE for COPD manual and training program being developed by health care professionals working within COPD services, it is unknown whether the program would be suitable to be delivered by non-health care professionals, and certain feedback is specific to the manual. This study may also have benefited from a larger, more heterogeneous sample including more male participants, though it was restricted by the responders to the advert. It is unclear whether having solely female participants has biased the results, but the authors acknowledge that the small sample, limited professional backgrounds and usage of a specific COPD manual (SPACE for COPD) limit the generalizability of this study. However, participants were representative of those who would feasibly be expected to deliver the program as part of their role.

\section{Implications for future research}

During the semistructured interviews, concerns were raised by more experienced staff that those with less experience in COPD may need further training or increased support during the implementation of the manual with patients. To date, there has been no formal follow-up of health care professionals to measure whether this increase in training time or support would be warranted, and so follow-up with quality assurance and intervention fidelity checks would be prudent, in addition to monitoring whether confidence in delivering the manual increased as a result of the training. It may be of interest to ask future trainees to record their job role and level of experience on their response to quantify whether there is a significant difference in knowledge between those with more and less experience. Within diabetes care it has been shown that lay educators can deliver structured education with no significant difference in outcome measures compared to health care professionals, ${ }^{24}$ though it was ensured that the lay educator was always paired with a more experienced health care professional. Once the SPACE for COPD program becomes established, this is an area that could be explored further, as well as monitoring outcome measures to ensure effectiveness.

The training program would benefit from ongoing evaluation to track whether modifications made as a result of feedback, such as increased information on exercise prescriptions and increased number of manual demonstrations during the face-to-face training, have been found to be helpful.

Another area that warrants further investigation is whether the findings from this study can be replicated in selfmanagement training programs for other chronic diseases such as those developed for patients with chronic kidney disease ${ }^{7,8}$ and Type 2 diabetes. ${ }^{9}$ A similar study within pain management for chronic musculoskeletal conditions found that facilitators requested more training in facilitation skills and that a fidelity assessment was required from the outset to measure the adherence and competence of those delivering 
the intervention. ${ }^{25}$ Research carried out into facilitation of the Diabetes Education and Self-Management for Ongoing and Newly Diagnosed (DESMOND) program has shown that facilitators valued self-reflection and peer review, but wanted greater emphasis on the quality development process during initial training, ${ }^{26}$ and this can be achieved using a virtual approach, which was found to be more objective and focused for both the assessor and educator. ${ }^{27}$

\section{Conclusion}

Fundamental knowledge and skills gaps appear to exist in health care professionals currently working with COPD patients. These gaps have been identified and used to inform the training requirements for health care professionals. Based on these requirements, a training program was designed and developed to ensure health care professionals can increase their knowledge of COPD and deliver the SPACE for COPD manual to patients at a standardized level. Once trained, it is hoped that these health care professionals will have the confidence to provide ongoing support to those patients working through the SPACE for COPD manual and ultimately improve the patients' management of COPD with an effective use of resources. This program has been shown to increase knowledge in relation to COPD self-management, was well received by health care professionals and is feasible to deliver within routine clinical practice.

\section{Acknowledgments}

The research was funded by the National Institute for Health Research (NIHR) Research for Patient Benefit Programme (grant PB-PG-0808-17146) and East Midlands Collaboration for Leadership in Applied Health Research and Care (CLAHRC) and took place at the University Hospitals of Leicester NHS Trust. Support was also provided by the NIHR Leicester Respiratory Biomedical Research Unit (BRU). The views expressed are those of the authors and not necessarily those of the NHS, the NIHR or the Department of Health.

The authors would like to acknowledge the contribution made by Samantha Harrison for contributing to the early preliminary analysis of the transcript.

\section{Disclosure}

The authors report no conflicts of interest in this work.

\section{References}

1. National Institute for Health and Clinical Excellence. Chronic Obstructive Pulmonary Disease in Over 16s: Diagnosis and Management. NICE Guidelines; 2010.

2. Gershon S, Warner L, Cascagnette P, Victor J, Charles T. Lifetime risk of developing chronic obstructive pulmonary disease: a longitudinal population study. Lancet (London, England). 2011;378(9795):991.
3. Apps D, Harrison L, Williams JEA, et al. How do informal self-care strategies evolve among patients with chronic obstructive pulmonary disease managed in primary care? A qualitative study. Int J Chron Obstruct Pulmon Dis. 2014;9:257.

4. Young ML, Apps D, Harrison L, Johnson-Warrington L, Hudson N, Singh J. Important, misunderstood, and challenging: a qualitative study of nurses' and allied health professionals' perceptions of implementing self-management for patients with COPD. Int J Chron Obstruct Pulmon Dis. 2015;10:1043.

5. NHS England. Five Year Forward View. Wakefield: NHS England; 2014.

6. Steve R, Karl W, Debbie B, Diane L, Jane S, Alan W. 'It's coming at things from a very different standpoint: evaluating the "Supporting Self-Care in General Practice Programme" in NHS East of England. Prim Health Care Res Dev. 2013;14(2):113.

7. Byrne J, Khunti K, Stone M, Farooqi A, Carr S. Feasibility of a structured group education session to improve self-management of blood pressure in people with chronic kidney disease: an open randomised pilot trial. BMJ Open. 2011;1(2):e000381.

8. Chen S, Tsai Y, Sun C, Wu I, Lee C, Wu M. The impact of selfmanagement support on the progression of chronic kidney disease - a prospective randomized controlled trial. Nephrol Dial Transplant. 2011; 26(11):3560.

9. Davies MJ. Effectiveness of the diabetes education and self management for ongoing and newly diagnosed (DESMOND) programme for people with newly diagnosed type 2 diabetes: cluster randomised controlled trial. Br Med J. 2008;336(7642):491-495.

10. Bourbeau J, van der Palen J. Promoting effective self-management programmes to improve COPD. Eur Respir J. 2009;33(3):461.

11. Bourbeau J, Nault D. Self-management strategies in chronic obstructive pulmonary disease. Clin Chest Med. 2007;28(3):617.

12. Effing T, Monninkhof EM, van der Valk PD, et al. Self-management education for patients with chronic obstructive pulmonary disease. Cochrane Database Syst Rev. 2007;(4):CD002990.

13. Effing W, Bourbeau J, Vercoulen J, et al. Self-management programmes for COPD: moving forward. Chron Respir Dis. 2012;9(1):27.

14. Bourbeau J, Collet JP, Schwartzman K, Ducruet T, Nault D, Bradley C. Economic benefits of self-management education in COPD. Chest. 2006;130(6):1704-1712.

15. Apps LD, Mitchell KE, Harrison SL, et al. The development and pilot testing of the Self-management Programme of Activity, Coping and Education for Chronic Obstructive Pulmonary Disease (SPACE for COPD). Int J Chron Obstruct Pulmon Dis. 2013;8:317-327.

16. Mitchell E, Johnson-Warrington V, Apps D, et al. A self-management programme for COPD: a randomised controlled trial. Eur Respir J. 2014;44(6): 1538

17. Horton E, Mitchell K, Johnson-Warrington V, Apps L, Young H, Singh $\mathrm{S}$. A self-management programme of activity, coping and education (SPACE) for COPD: a randomised non-inferiority trial in a pulmonary rehabilitation population. Thorax. 2013;68(suppl 3):A15-A16.

18. Mudge S, Kayes N, McPherson K. Who is in control? Clinicians' view on their role in self-management approaches: a qualitative metasynthesis. BMJ Open. 2015;5(5):e007413.

19. Rogers A, Kennedy A, Nelson E, Robinson A. Uncovering the limits of patient-centeredness: implementing a self-management trial for chronic illness. Qual Health Res. 2005;15(2):224-240.

20. Braun V, Clarke V. Using thematic analysis in psychology. Qual Res Psychol. 2006;3(2):77.

21. Kennedy A, Chew-Graham C, Blakeman T, et al. Delivering the WISE (whole systems informing self-management engagement) training package in primary care: learning from formative evaluation. Implement Sci. 2010;5:7.

22. Zwerink M, Brusse-Keizer M, van der Valk PD, et al. Self-management for patients with chronic obstructive pulmonary disease. Cochrane Database Syst Rev. 2014;(3):CD002990.

23. White R, Walker P, Roberts S, Kalisky S, White P. Bristol COPD Knowledge Questionnaire (BCKQ): testing what we teach patients about COPD. Chron Respir Dis. 2006;3(3):123. 
24. Carey ME, Mandalia P, Cradock S, et al. The DESMOND Lay Educator study: testing a training programme for lay educators to deliver the DESMOND (diabetes education and self-management for ongoing and newly diagnosed) programme in partnership with healthcare professional educators. Diabetic Med. 2012;29:19-20.

25. Carnes D, Homer K, Underwood M, Pincus T, Rahman A, Taylor JC. Pain management for chronic musculoskeletal conditions: the development of an evidence-based and theory-informed pain self-management course. BMJ Open. 2013;3(11):e003534.
26. Taylor C, Cradock S, Stribling B, et al. Quality development: what it means to DESMOND educators. Diabetic Med. 2011;28:123.

27. Cradock S, Taylor C, Rodgers A, Stribling B. Quality assurance across the oceans: assessing the quality of delivery of structured self-management education using a virtual approach from the UK to Gibraltar and Australia. Diabetic Med. 2013;30:116. 


\section{Supplementary materials Interview schedule}

Interview schedule for health care professional interviews

\section{Gain consent and introduction}

Introduce yourself, name and role

You have consented to taking part in an interview, which is an informal chat with me. We will be discussing issues regarding self-management, COPD, delivery of the selfmanagement manual for patients with COPD and training needs regarding this.

\section{Do you have any questions?}

Are you happy with me to turn on the dictaphone to record the interview as it takes place?

For the benefit of the tape, it is ... day ... time and present there is me,... (the participant) and ...

Before we start, I just have a few questions that you can answer yes or no to:

- Do you understand what the interview is about?

- Do you understand the purpose of the interview?

- Are you happy to take part in the interview and for it to be recorded?

\section{Ground rules}

Everything that is said during the next hour and a half is confidential. If, however, you do disclose any information that highlights a breach of the law or a dangerous practice, I will be duty bound to break confidentiality. This means that if during the session you tell me you have broken the law or done something dangerous that may result in harm to yourself or others, I will have to report to the necessary people.

\section{Withdrawal}

If anything we speak about today does make you feel uncomfortable you are free to not answer a particular question, request for the recorder to be switched off and to resume the interview after a short break or you can ask to terminate the interview all together at any point. If after this discussion has taken place you wish to remove your comments from the study, please contact me or another researcher on the study, and none of your comments will be taken into account when performing the analysis.

\section{Current role/COPD strategies}

- Can you tell me a little about what you do for patients with COPD whom you have contact with? Are there any current strategies you use? Anything you would like to be able to do with these patients? Do you see them regularly? What do you do when they are first diagnosed? Do you offer any interventions/support?

\section{Self-management}

- What do you understand by the term "self-management"? Patients independently doing something to help themselves. Self-management is the term given to the way persons manage their life and lifestyle to optimize their health, well-being and quality of life.

- Do you think self-management is important for patients with COPD? If yes, in what ways? If not, why not?

- How well do you think you currently help patients to self-manage their COPD? What do you do to help this? Any difficulties in doing this?

- Do you feel there are any barriers for patients to adopt self-management strategies? Lack of motivation? Do you find it difficult to motivate patients? How do you motivate patients? Unable/unwilling to take advice on board?

\section{The manual}

You have had a chance to look at the manual, is there anything you would like to comment on? Are there any areas within the manual that you feel you may need more knowledge on (look at contents page)? Is there anything in there you are unsure about - exercise/activity/medication/education or advice?

- How would you feel about introducing this manual to a patient with COPD? What barriers do you think you may have in doing this? What would you feel most confident in doing?

- How would you support patients who have this manual? Telephone calls to help patients? How would you feel about doing this - any barriers or help needed? Ongoing support?

- Would you assess or follow-up these patients to find out if they were benefiting from this manual? How would you do this? Formal or informal? Do you feel it is important to measure change in patients' physical performance, quality of life or other aspect of their well-being? Would you measure a change in patient's exercise levels, that is, walking tests? Would you use questionnaires or interviews to measure knowledge or Quality of Life? Any problems in doing this?

\section{Training}

Do you feel you would need help or training in order to deliver the manual to patients with COPD effectively? If so, why? What parts in particular? If no, why not?

- What would be the best way of delivering this training? On the job, observation, web-based, training day, 
telephone/email support? One-off training, few days or continued support?

- Do you feel you would need ongoing support or resources? If yes, in what ways? If no, why not? Best way to provide this?

- Any problems with being able to train? Time, cost, staff?
I have asked all the questions I would like to now. Do you have anything you feel like you would like to add?

Thank you very much for all your time and comments. I will turn off the dictaphone now.

International Journal of COPD

\section{Publish your work in this journal}

The International Journal of COPD is an international, peer-reviewed journal of therapeutics and pharmacology focusing on concise rapid reporting of clinical studies and reviews in COPD. Special focus is given to the pathophysiological processes underlying the disease, intervention programs, patient focused education, and self management protocols. manuscript management system is completely online and includes a very quick and fair peer-review system, which is all easy to use. Visit http://www.dovepress.com/testimonials.php to read real quotes from published authors. 